\title{
The New Approach to the Preparation of Polyacrylamide-Based Hydrogels: Initiation of Polymerization of Acrylamide with 1,3-Dimethylimidazolium (Phosphonooxy-)Oligosulphanide under Drying Aqueous Solutions
}

\author{
Natalia Tarasova ${ }^{1,2}$, Alexey Zanin ${ }^{1, *(D)}$, Efrem Krivoborodov ${ }^{1}$, Ilya Toropygin ${ }^{3}$, Ekaterina Pascal ${ }^{1}$ and \\ Yaroslav Mezhuev ${ }^{1}$
}

check for updates

Citation: Tarasova, N.; Zanin, A Krivoborodov, E.; Toropygin, I.; Pascal, E.; Mezhuev, Y. The New Approach to the Preparation of Polyacrylamide-Based Hydrogels: Initiation of Polymerization of Acrylamide with 1,3-

\section{Dimethylimidazolium}

(Phosphonooxy-)Oligosulphanide under Drying Aqueous Solutions.

Polymers 2021, 13, 1806

https://doi.org/10.3390/

polym13111806

Academic Editor: Adriana Kovalcik

Received: 9 May 2021

Accepted: 27 May 2021

Published: 30 May 2021

Publisher's Note: MDPI stays neutral with regard to jurisdictional claims in published maps and institutional affiliations.

Copyright: (C) 2021 by the authors. Licensee MDPI, Basel, Switzerland. This article is an open access article distributed under the terms and conditions of the Creative Commons Attribution (CC BY) license (https:// creativecommons.org/licenses/by/ $4.0 /)$
1 Institute of Chemistry and Problems of Sustainable Development, Dmitry Mendeleev University of Chemical Technology of Russia, 12047 Moscow, Russia; tarasnp@muctr.ru (N.T.); iEfrem@muctr.ru (E.K.); 201221@muctr.ru (E.P.); yamezhuev@muctr.ru (Y.M.)

2 Institute of Geology of Ore Deposits, Petrography, Mineralogy, and Geochemistry, Russian Academy of Sciences, 119017 Moscow, Russia

3 V.N. Orekhovich Research Institute of Biomedical Chemistry, Russian Academy of Medical Sciences, 119121 Moscow, Russia; ilya@ibmh.msk.su

* Correspondence: zanin@muctr.ru

\begin{abstract}
The new initiator of the polymerization of acrylamide, leading to the formation of crosslinked polyacrylamide, was discovered. The structure of the synthesized polyacrylamide was characterized by XRD, ${ }^{1} \mathrm{H}$ NMR, and ${ }^{13} \mathrm{C}$ NMR spectroscopy. It was shown that $1,3-$ dimethylimidazolium (phosphonooxy-)oligosulphanide is able to initiate radical polymerization under drying aqueous solutions of acrylamide, even at room temperature. According to XRF data, the synthesized polyacrylamide gel contains $0.28 \mathrm{wt} \%$ of sulphur. The formed polymer network has a low crosslinking density and a high equilibrium degree of swelling. The swelling rate of polyacrylamide gel in water corresponds to the first order kinetic equation with the rate constant $6.2 \times 10^{-2} \mathrm{~min}^{-1}$. The initiator is promising for combining acrylamide polymerization with the processes of gel molding and drying.
\end{abstract}

Keywords: polyacrylamide; polymerization of acrylamide; polymerization initiator; ionic liquids; sulphur

\section{Introduction}

Linear and crosslinked polyacrylamide, as well as acrylamide copolymers, are of significant applied interest and are used in water treatment [1-3], enhanced oil recovery (EOR) technologies [3-6], stabilization of nanoparticles [7-9], electrophoresis-induced separation and purification of substances [10], and adsorption removal of $\mathrm{Pb}^{2+}$ ions from aqueous solutions [11]. The biocompatibility and hydrophilicity of polyacrylamide have ensured its wide application in biomedical fields [12], including in systems of pharmacologically active substance delivery [13] and the binding of toxins [14]. Several acrylamide copolymers have proven to be stimulus-sensitive polymers. For example, nanoparticles of a copolymer of acrylamide and acrylonitrile are described that are capable of transitioning from worm-like morphology to spherical when heated in water [15].

For biomedical applications, polymer networks based on crosslinked polyacrylamide, capable of large, limited swelling in water, which are obtained by radical copolymerization of acrylamide and methylene-bis-acrylamide, are of particular importance. Although polyacrylamide gels are widely used, significant difficulties arise in the need for polymerization molding of articles. Therefore, the development of a method that provides the initiation of acrylamide polymerization under the conditions of drying its aqueous 
solutions is an important applied problem. Although the kinetics and the mechanism of polyacrylamide synthesis have been thoroughly studied [16,17], the search for new methods of initiating the polymerization of acrylamide in mild conditions continues [18-20]. Earlier, we discovered the possibility of ring opening of cyclooctasulphur in the presence of 1,3-dimethylimidazolium dimethyl phosphate with the formation of phosphorylated linear sulphur oligomers (Scheme 1) [21].<smiles>COP(=O)([O-])OC</smiles>

Scheme 1. Synthesis of 1,3-dimethylimidazolium (phosphonooxy-)oligosulphanide.

This work shows for the first time the possibility of using 1,3-dimethylimidazolium (phosphonooxy-)oligosulphanide to initiate polymerization of acrylamide under conditions of prolonged drying of its aqueous solution at room temperature. As a result, the formation of a crosslinked polyacrylamide was observed in the absence of methylene-bis-acrylamide.

\section{Materials and Methods}

\subsection{Synthesis of Polyacrylamide in the Presence of 1,3-Dimethylimidazolium (Phosphonooxy-)Oligosulphanide}

$0.2 \mathrm{~mL}$ of a solution of 1,3-dimethylimidazolium (phosphonooxy-)oligosulphanide, obtained according to the previously described method [21], was added to a solution of 0.5 g of acrylamide ("Sigma-Aldrich", purity over 99\%, St. Louis, MI, USA) in $2 \mathrm{~mL}$ of water (bidistillate), followed by stirring for $20 \mathrm{~min}$. Then the reaction mixture was left at a temperature of $298 \mathrm{~K}\left(25^{\circ} \mathrm{C}\right)$ and dried. The structure of the obtained polyacrylamide was characterized by XRD (Benchtop X-ray Diffractometer, Malvern Panalytical Aeris XRD) and X-ray fluorescent analysis (Bruker Kappa APEX DUO).

The dynamics of acrylamide polymerization was investigated in situ in an open ampoule, daily recording the ${ }^{1} \mathrm{H}$ NMR spectrum (Bruker CXP 200) of the reaction system. For the sample isolated four days after the start of the reaction and washing with methanol (in the calculation of $10 \mathrm{~mL}$ of $\mathrm{CH}_{3} \mathrm{OH}$ ("Sigma-Aldrich", purity over 99\%) per $1 \mathrm{~g}$ of gel), the ${ }^{13} \mathrm{C}$ NMR spectrum was recorded.

\subsection{Swelling Kinetics of Polyacrylamide in Water}

$0.115 \mathrm{~g}$ of synthesized polyacrylamide, thoroughly washed with methanol and dried, was placed in $100 \mathrm{~mL}$ of water. The system was thermostated at $298 \mathrm{~K}\left(25^{\circ} \mathrm{C}\right)$, and the mass of the sample was recorded at specified time intervals.

\section{Results and Discussion}

The ${ }^{1} \mathrm{H}$ NMR spectrum contains signals of $5.69 \mathrm{ppm}$ and $6.10 \mathrm{ppm}$ related to the vinyl moiety of the residual acrylamide (Figure 1A), as well as signals of $2.07 \mathrm{ppm}$ and $1.52 \mathrm{ppm}$, belonging to the $\mathrm{CH}$ and $\mathrm{CH}_{2}$ groups of the polyacrylamide chain (Figure 1D). The assignment of signals on the ${ }^{13} \mathrm{C}$ NMR and ${ }^{1} \mathrm{H}$ NMR spectra of polyacrylamide gels are consistent with the previously described outcomes [22,23]. The ${ }^{1} \mathrm{H}$ NMR spectra of the reaction system, obtained during the drying of an aqueous solution of acrylamide in the presence of 1,3-dimethylimidazolium (phosphonooxy-)oligosulphanide, indicate the gradual formation of polyacrylamide (Figure 1). The reaction proceeds almost until the complete conversion of the monomer, so that after 6 days no vinyl proton signals of the initial acrylamide were observed in the ${ }^{1} \mathrm{H}$ NMR spectrum of the reaction system (Figure 1D). 


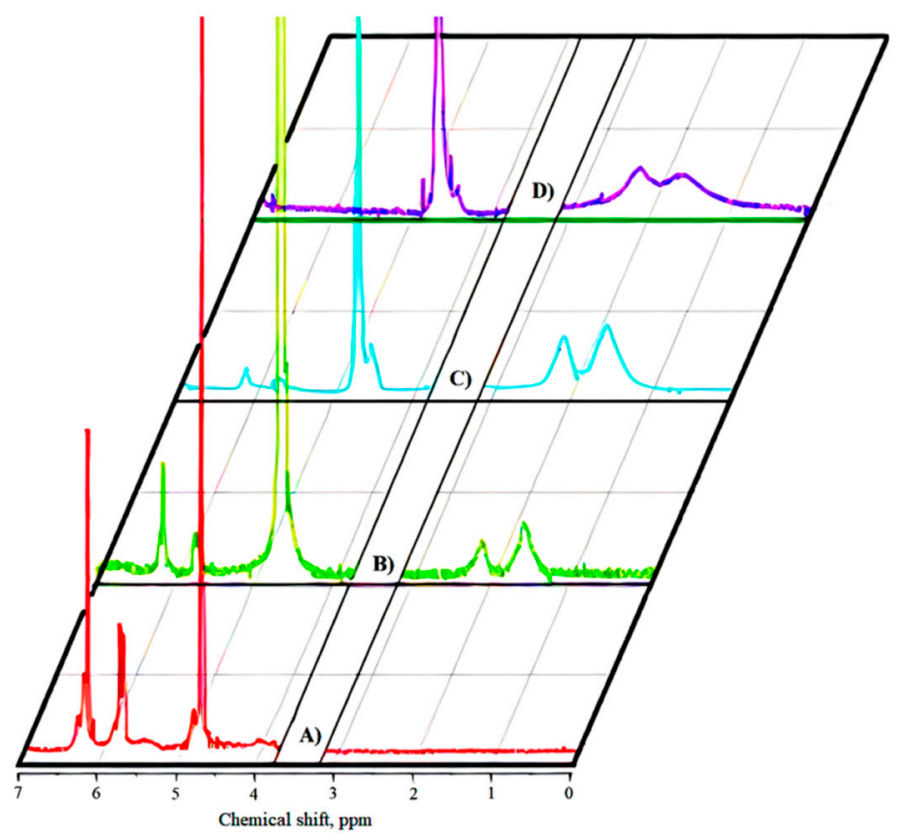

Figure 1. The ${ }^{1} \mathrm{H}$ NMR spectra of the reaction system obtained in the process of drying an aqueous solution of acrylamide at a temperature of $298 \mathrm{~K}\left(25^{\circ} \mathrm{C}\right)$ after: (A) 1 day; (B) 4 days; (C) 5 days; (D) 6 days after the start of the reaction.

It is noteworthy that polymerization begins only when most of the water has been removed and does not develop in a sealed ampoule. The polymerization of acrylamide in the presence of 1,3-dimethylimidazolium (phosphonooxy-)oligosulphanide is evidenced by the ${ }^{13} \mathrm{C}$ NMR spectrum recorded in $\mathrm{D}_{2} \mathrm{O}$ for gel washed with methanol (Figure 2). As observed, the ${ }^{13} \mathrm{C}$ NMR spectrum contains signals of $171 \mathrm{ppm}, 129.99 \mathrm{ppm}$ and $128.99 \mathrm{ppm}$ related to the carbon atoms of residual acrylamide, as well as signals of $180.00 \mathrm{ppm}$, $42.25 \mathrm{ppm}$ and $35.77 \mathrm{ppm}$, related to the carbon atoms of the $\mathrm{C}=\mathrm{O}, \mathrm{CH}$ and $\mathrm{CH}_{2}$ moieties of the resulting polyacrylamide. The signal with a chemical shift of $50 \mathrm{ppm}$ refers to the methanol carbon used for rinsing.
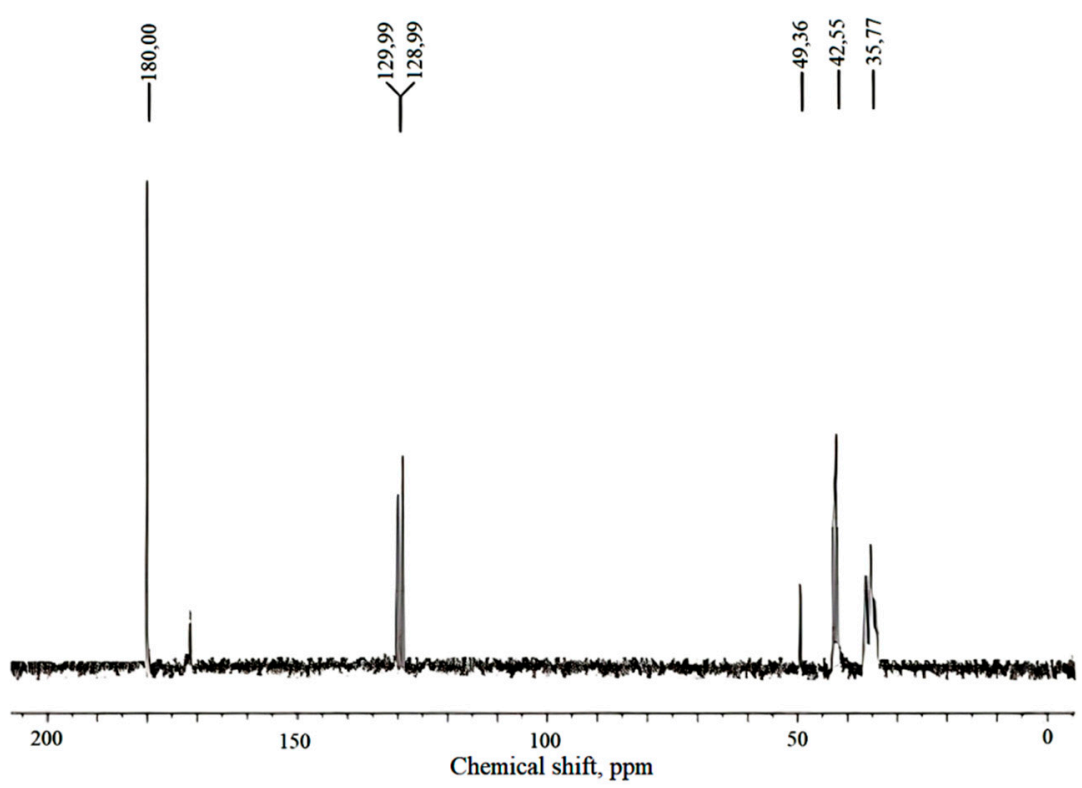

Figure $2 .{ }^{13} \mathrm{C}$ NMR spectrum of polyacrylamide gel after rinsing with methanol at the rate of $10 \mathrm{~mL}$ of $\mathrm{CH}_{3} \mathrm{OH}$ per $1 \mathrm{~g}$ of crosslinked polymer. 
XRD data indicate the formation of an amorphous substance, which is characteristic of polyacrylamide (Figure 3) [24]. According to X-ray fluorescent analysis, the mass proportion of sulphur within the polyacrylamide gel sample repeatedly purified by rinsing with methanol and distilled water is $0.28 \mathrm{wt} \%$, while the ${ }^{31} \mathrm{P}$ NMR spectrum recorded by using methanol for rinsing shows a singlet with a chemical shift of $3.28 \mathrm{ppm}$ (relative to $85 \%$ aqueous phosphoric acid), which is characteristic for the phosphorus atom of the dimethyl phosphate anion.

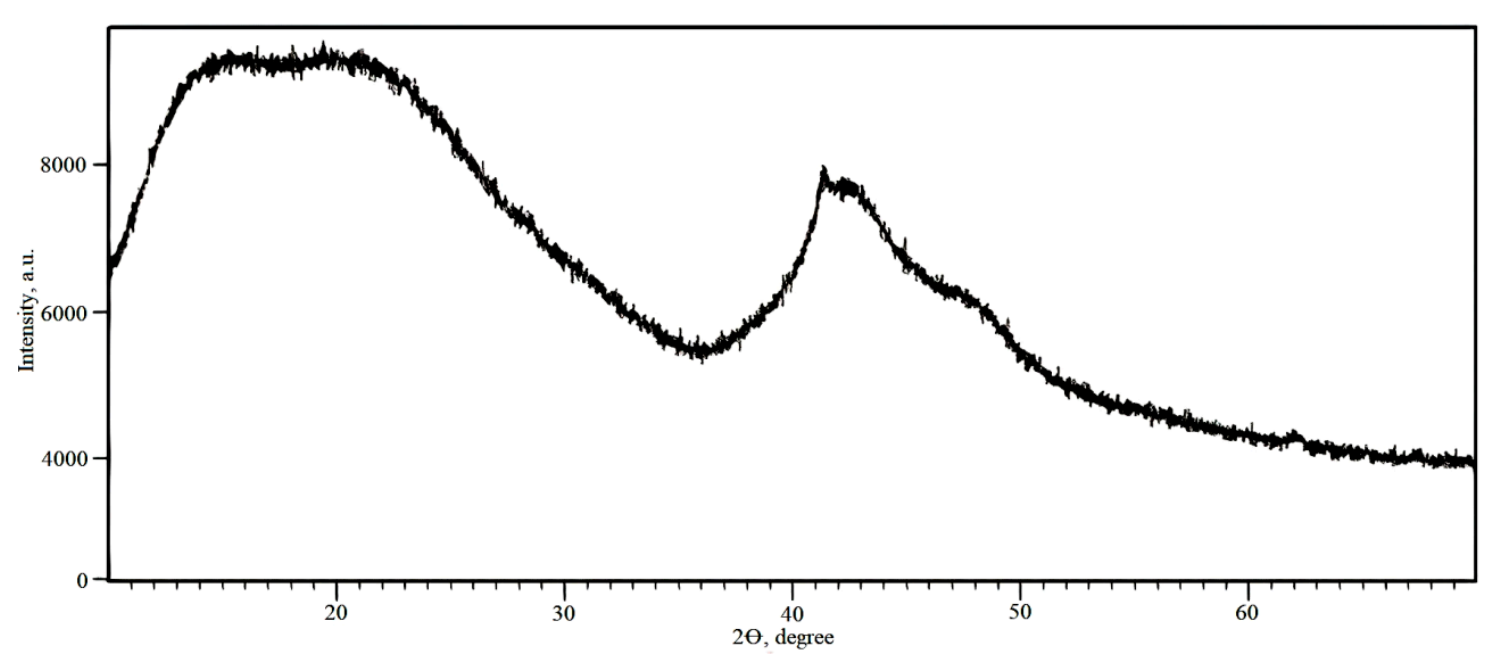

Figure 3. XRD of dried polyacrylamide gel.

The synthesized polyacrylamide was only capable of limited swelling in water, which indicates the formation of a three-dimensional polymer network (Figure 4). The linearity of the kinetic curve of the swelling of polyacrylamide in water in coordinates $\ln \left[\frac{\left(\alpha_{\infty}-\alpha\right)}{\alpha_{\infty}}\right]$ vs. $t$ indicates the subordination of the process to the quasi-first order Equation (1) and its integral form (2):

$$
\begin{gathered}
\frac{d \alpha}{d t}=k\left(\alpha_{\infty}-\alpha\right) \\
\ln \left[\frac{\left(\alpha_{\infty}-\alpha\right)}{\alpha_{\infty}}\right]=-k t
\end{gathered}
$$

where: $\alpha=\left(m-m_{0}\right) / m_{0}$-the degree of swelling and $\alpha_{\infty}$-the equilibrium degree of swelling of the polyacrylamide gel in water; $m_{0}, m$-initial and current value of gel weight; $t$-time; $k$-swelling rate constant.

The swelling rate constant of polyacrylamide in water was $6.2 \times 10^{-2} \mathrm{~min}^{-1}$, and the equilibrium degree of swelling is 7.09. The obtained kinetic data make it possible to quantitatively estimate the average molecular weight of the chain segments between the network nodes according to the Flory and Rehner Equation (3) [25]:

$$
\bar{M}_{\mathcal{C}}=-\frac{d_{P} V_{m S}\left(\varphi^{\frac{1}{3}}-0.5 \varphi\right)}{\ln (1-\varphi)+\varphi+\chi \varphi^{2}}
$$

where: $\bar{M}_{c}$ —average molecular weight of chain segments between network nodes; $\varphi-$ volume fraction of the polymer that has reached equilibrium swelling; $d_{P}$-density of the polymer; $V_{m S}-$ molar volume of the solvent; $\chi$-Huggins interaction parameter. 

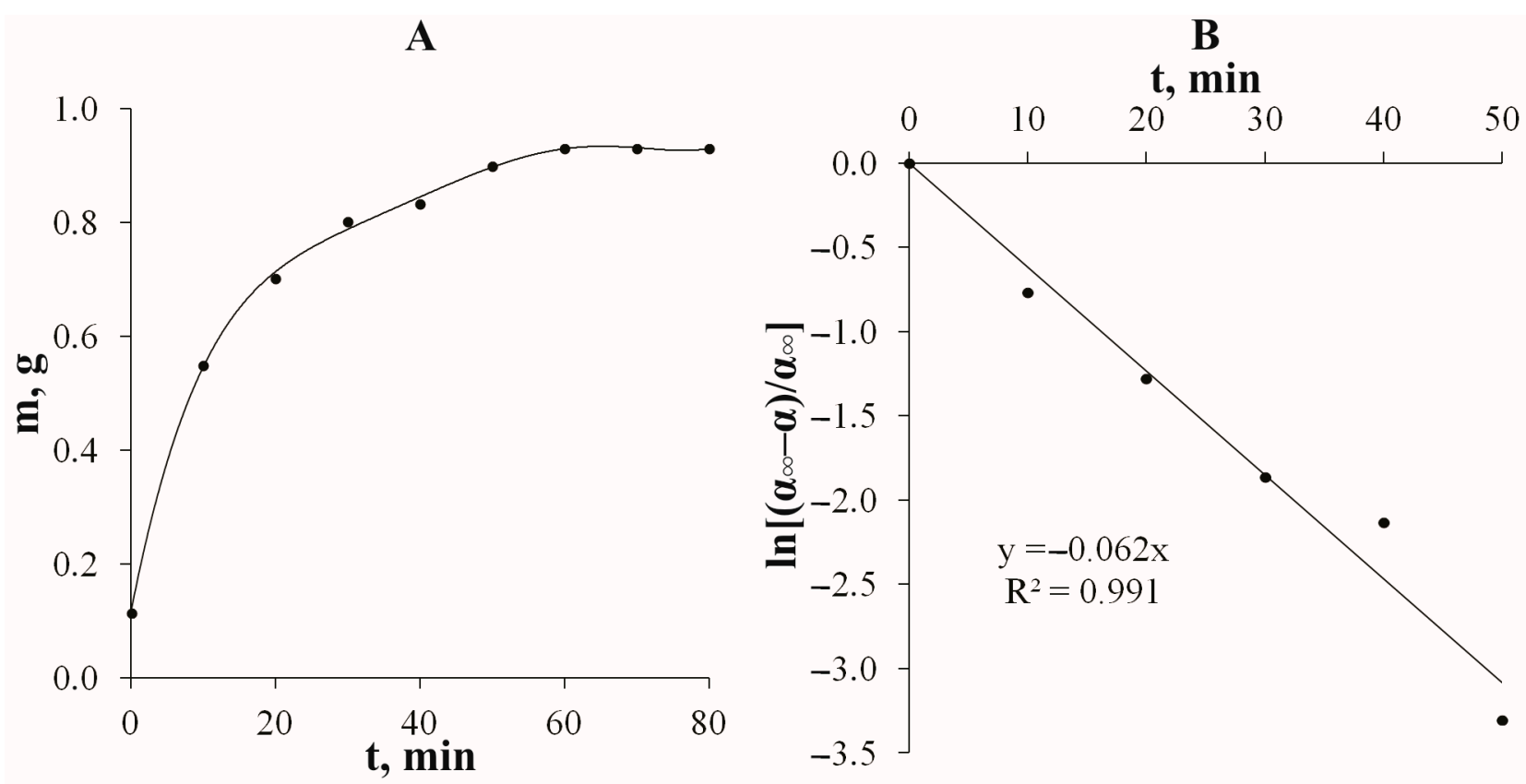

Figure 4. Kinetic curves of the swelling of polyacrylamide in water at a temperature of $298 \mathrm{~K}\left(25^{\circ} \mathrm{C}\right)$ in coordinates: (A) - $m$ vs. $\mathrm{t} ;(\mathbf{B})-\ln \left[\frac{\left(\alpha_{\infty}-\alpha\right)}{\alpha_{\infty}}\right]$ vs. $t$, where $m$-current value of gel weight.

Taking into account the density of polyacrylamide $1.3 \mathrm{~g} \times \mathrm{cm}^{-3}$, the volume fraction of the polymer $(\varphi)$ upon reaching the equilibrium degree of swelling is 0.098 . Since the Huggins interaction parameter for the polyacrylamide-water system is close to 0.493 at a temperature of $298 \mathrm{~K}\left(25^{\circ} \mathrm{C}\right)$ [26], $\bar{M}_{c}$ is about $10^{4}$. Therefore, the use of 1,3dimethylimidazolium (phosphonooxy-)oligosulphanide as an initiator of acrylamide polymerization under conditions of slow drying of its aqueous solutions allows the formation of a lightly crosslinked polymer network with high water absorption.

The listed circumstances can be explained if we admit the mechanism shown in Scheme 2. In accordance with this mechanism, the initiation of polymerization is possible only under the condition of a high concentration of acrylamide in the reaction system. In addition, according to the HSAB theory, only a low rate of processes leading to chain crosslinking can be expected, which is consistent with the formation of polymer gels with a high equilibrium degree of swelling and low crosslinking density.

The possibility of initiating polymerization of acrylamide with 1,3-dimethylimidazolium (phosphonooxy-)oligosulphanide is consistent with the increased ability for the formation of S-S bonds to homolytic decomposition, compared to $\mathrm{S}_{8}$ [27-31] and the low stability of hydrogen polysulphides. Although the details of the mechanism of the reaction described above have yet to be established, we report on the fundamental possibility of initiating radical polymerization of acrylamide with 1,3-dimethylimidazolium (phosphonooxy-) oligosulphanide. 

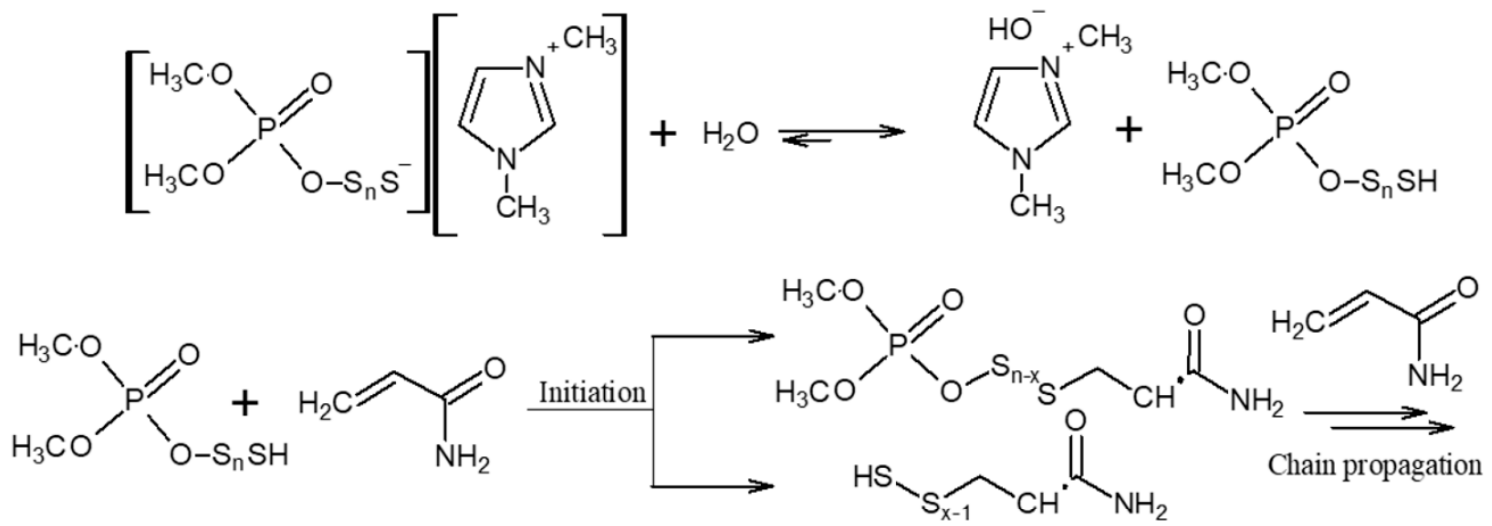

Crosslink

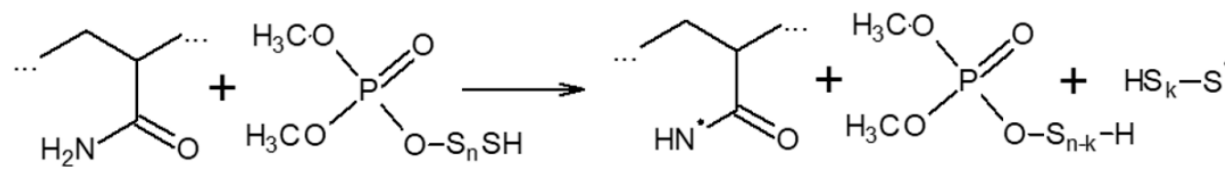

2

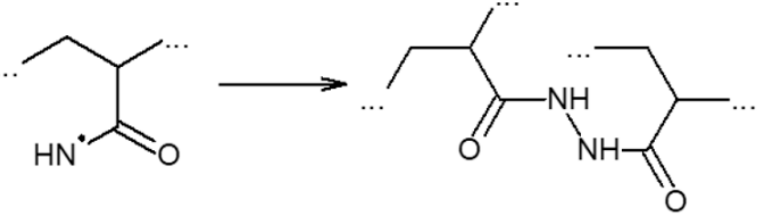

Scheme 2. The proposed mechanism for the formation of crosslinked polyacrylamide in the presence of 1,3dimethylimidazolium (phosphonooxy-)oligosulphanide.

\section{Conclusions}

The product of the interaction of elemental sulphur with 1,3-dimethylimidazolium dimethylphosphate is capable of initiating acrylamide polymerization upon the slow evaporation of water at room temperature. The resulting polyacrylamide is capable of limited swelling in water, and the equilibrium mass degree of swelling is 7.09, and the swelling rate constant at a temperature of $298 \mathrm{~K}\left(25^{\circ} \mathrm{C}\right)$ is $6.2 \times 10^{-2} \mathrm{~min}^{-1}$. Thus, simultaneously with the formation of polyacrylamide chains, the process responsible for their crosslinking develops, which opens the possibility of obtaining polymer networks by drying aqueous solutions of acrylamide. This reaction opens new perspectives and modes of forming articles from crosslinked polyacrylamide.

Apparently, both the initiation of polymerization of acrylamide and the crosslinking of the chains of the resulting polyacrylamide are a consequence of the low stability of the S-S bonds of linear sulphur chains of 1,3-dimethylimidazolium (phosphonooxy-) oligosulphanide.

Author Contributions: Conceptualization, N.T.; methodology, E.K. and I.T.; validation, E.K., I.T. and E.P.; formal analysis, E.K. and I.T.; investigation, I.T.; resources, E.K. and E.P.; data curation, E.K.; writing—original draft preparation, E.K. and Y.M.; writing—review and editing, N.T., A.Z. and Y.M.; visualization, A.Z., E.K. and Y.M.; supervision, N.T. and A.Z.; project administration, N.T. and A.Z.; funding acquisition, A.Z. All authors have read and agreed to the published version of the manuscript.

Funding: This research was funded by D. Mendeleev University of Chemical Technology of Russia, grant number 2020-040.

Institutional Review Board Statement: Not applicable.

Informed Consent Statement: Not applicable.

Data Availability Statement: Not applicable. 
Acknowledgments: This research was funded by D. Mendeleev University of Chemical Technology of Russia, grant number 2020-040.

Conflicts of Interest: The authors declare no conflict of interest.

\section{References}

1. Myagchenkov, V.A.; Kurenkov, V.F. Applications of Acrylamide Polymers and Copolymers: A Review. Polym. Plast. Technol. Eng. 1991, 30, 109-135. [CrossRef]

2. Daifa, M.; Shmoeli, E.; Domb, A.J. Enhanced flocculation activity of polyacrylamide-based flocculant for purification of industrial wastewater. Polym. Adv. Technol. 2019, 30, 2636-2646. [CrossRef]

3. Xiong, B.; Loss, R.D.; Shields, D. Polyacrylamide degradation and its implications in environmental systems. NPJ Clean Water 2018, 1, 17. [CrossRef]

4. Xian'e, L.; Zhi, X.; Hongyao, Y.; Yujun, F.; Hongping, Q. Comparative Studies on Enhanced Oil Recovery: Thermoviscosifying Polymer Versus Polyacrylamide. Energy Fuels 2017, 31, 2479-2487.

5. Du, W.; Slaný, M.; Wang, X.; Chen, G.; Zhang, J. The Inhibition Property and Mechanism of a Novel Low Molecular Weight Zwitterionic Copolymer for Improving Wellbore Stability. Polymers 2020, 12, 708. [CrossRef]

6. Cao, J.; Song, T.; Zhu, Y.; Wang, X.; Wang, S.; Yu, J.; Zhang, J. Aqueous hybrids of amino-functionalized nanosilica and acrylamide-based polymer for enhanced oil recovery. RSC Adv. 2018, 8, 38056-38064. [CrossRef]

7. Cheraghian, G. Synthesis and properties of polyacrylamide by nanoparticles, effect nanoclay on stability polyacrylamide solution. Micro Nano Lett. 2017, 12, 40-44. [CrossRef]

8. Mirzaie Yegane, M.; Hashemi, F.; Vercauteren, F.; Meulendijks, N.; Gharbi, R.; Boukany, P.E.; Zitha, P. Rheological response of a modified polyacrylamide-silica nanoparticles hybrid at high salinity and temperature. Soft Matter. 2020, 16, 10198-10210. [CrossRef]

9. Haruna, M.A.; Gardy, J.; Yao, G.; Hu, Z.; Hondow, N.; Wen, D. Nanoparticle modified polyacrylamide for enhanced oil recovery at harsh conditions. Fuel 2020, 268, 117186. [CrossRef]

10. Chrambach, A.; Rodbard, D. Polyacrylamide Gel Electrophoresis. Science 1971, 172, 440-451. [CrossRef]

11. Chen, Y.; Li, Q.; Li, Y.; Zhang, Q.; Huang, J.; Wu, Q.; Wang, S. Fabrication of Cellulose Nanocrystal-g-Poly(Acrylic Acid-CoAcrylamide) Aerogels for Efficient $\mathrm{Pb}(\mathrm{II})$ Removal. Polymers 2020, 12, 333. [CrossRef]

12. Judah, H.L.; Liu, P.; Zarbakhsh, A.; Resmini, M. Influence of Buffers, Ionic Strength, and pH on the Volume Phase Transition Behavior of Acrylamide-Based Nanogels. Polymers 2020, 12, 2590. [CrossRef]

13. Hibbins, A.R.; Kumar, P.; Choonara, Y.E.; Kondiah, P.P.D.; Marimuthu, T.; Du Toit, L.C.; Pillay, V. Design of a Versatile pHResponsive Hydrogel for Potential Oral Delivery of Gastric-Sensitive Bioactives. Polymers 2017, 9, 474. [CrossRef]

14. Yang, T.H. Recent Applications of Polyacrylamide as Biomaterials. Recent Pat. Mater. Sci. 2008, 1, 29-40. [CrossRef]

15. Audureau, N.; Coumes, F.; Guigner, J.; Nguyen, T.; Menager, C.; Stoffelbach, F.; Rieger, J. Thermoresponsive properties of poly(acrylamide-co-acrylonitrile)-based diblock copolymers synthesized (by PISA) in water. Polym. Chem. 2020, 11, 5998-6008. [CrossRef]

16. Kurenkov, V.F.; Myagchenkov, V.A. Effects of reaction medium on the radical polymerization and copolymerization of acrylamide. Eur. Polym. J. 1980, 16, 1229-1239. [CrossRef]

17. Lee, G.H.; Vo, N.D.; Jeon, R.Y.; Han, S.W.; Hong, S.U.; Oh, M. Modeling and simulation for acrylamide polymerization of super absorbent polymer. Korean J. Chem. Eng. 2018, 35, 1791-1799. [CrossRef]

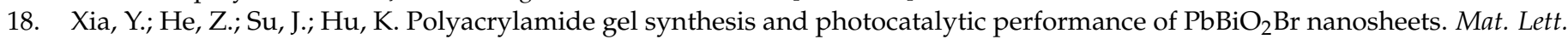
2019, 241, 64-67. [CrossRef]

19. Sánchez-Leija, R.J.; Torres-Lubián, J.R.; Reséndiz-Rubio, A.; Luna-Bárcenas, G.; Mota-Morales, J.D. Enzyme-mediated free radical polymerization of acrylamide in deep eutectic solvents. RSC Adv. 2016, 6, 13072-13079. [CrossRef]

20. Kumar, A.; Behera, B.; Ray, S.S. Microwave-assisted surface-initiated redox polymerization of acrylamide with functionalized graphene oxide for aqueous lubricant additive. RSC Adv. 2015, 5, 39474-39481. [CrossRef]

21. Tarasova, N.; Krivoborodov, E.; Egorova, A.; Zanin, A.; Glukhov, L.; Toropygin, I.; Mezhuev, Y. Reaction of 1,3dimethylimidazolium dimethylphosphate with elemental sulfur. Pure Appl. Chem. 2020, 92, 1297-1304. [CrossRef]

22. Lopatin, V.V.; Berestnev, V.A.; Askadskii, A.A.; Peregudov, A.S.; Shekhter, A.B. Structure and properties of polyacrylamide gels for medical applications. Polym. Bull. Ser. A 2004, 46, 1282-1292.

23. Al-Sabagh, A.M.; Kandile, N.G.; El-Ghazawy, R.A.; Noor El-Din, M.R.; El-sharaky, E.A. Synthesis and characterization of high molecular weight hydrophobically modified polyacrylamide nanolatexes using novel nonionic polymerizable surfactants. Egypt. J. Pet. 2013, 22, 531-538. [CrossRef]

24. Moulay, S.; Bensacia, N.; Garin, F.; Fechete, I.; Boos, A. Polyacrylamide-Based Sorbents for the Removal of Hazardous Metals. Adsorp. Sci. Technol. 2013, 31, 691-709. [CrossRef]

25. Zang, Y.; Muller, R.; Froelich, D. Determination of crosslinking density of polymer networks by mechanical data in simple extension and by swelling degree at equilibrium. Polymer 1989, 30, 2060-2062. [CrossRef]

26. Baselga, J.; Hernández-Fuentes, I.; Masegosa, R.; Llorente, M. Effect of Crosslinker on Swelling and Thermodynamic Properties of Polyacrylamide Gels. Polym. J. 1989, 21, 467-474. [CrossRef] 
27. Hodgson, W.G.; Buckler, S.A.; Peters, G. Free Radicals in Amine Solutions of Elemental Sulfur. J. Am. Chem. Soc. 1963, 85, 543-546. [CrossRef]

28. Zhang, Y.; Pavlopoulos, N.G.; Kleine, T.S.; Karayilan, M.; Glass, R.S.; Char, K.; Pyun, J. Nucleophilic Activation of Elemental Sulfur for Inverse Vulcanization and Dynamic Covalent Polymerizations. Polym. Sci. Part A Polym. Chem. 2019, 57, 7-12. [CrossRef]

29. Parker, D.J.; Chong, S.T.; Hasell, T. Sustainable inverse-vulcanised sulfur polymers. RSC Adv. 2018, 8, 27892-27899. [CrossRef]

30. Zhang, Y.; Glass, R.S.; Char, K.; Pyun, J. Recent advances in the polymerization of elemental sulphur, inverse vulcanization and methods to obtain functional Chalcogenide Hybrid Inorganic/Organic Polymers (CHIPs). Polym. Chem. 2019, 10, $4078-4105$. [CrossRef]

31. Liu, H.; Radford, M.N.; Yang, C.; Chen, W.; Xian, M. Inorganic hydrogen polysulfides: Chemistry, chemical biology and detection. Br. J. Pharmacol. 2019, 176, 616-627. [CrossRef] [PubMed] 